rally thus complicated, the different tribes internarying but little. They are said not to be as prolific as the whites.

Their religion, Mr. S. says, seems to consist chiefly of worship. ping the sun at certain periods of the moon. This they do at sunrise by various dances and incantations. They fully believe that they go down into the earth after death, and that in that other life they have the same bodies as now, though without the bones-a shrewd theology, and one which one of them who was buried in a trance corroborated by telling the rest that he was sent back to this world becauso he brought his bones with bim. Suspended animation, Mr. S. says, is rather common amongst them. He had an interesting allegorical painting, copied from the original, which was meant to represent the origin of thunder. Tho main figure was evidently intended for a whale, around which were several scrpentheaded, hippocampus tailed minor monsters, and abovo them a large, grotesque, englc-like bird, the thunder bird. The theory, he says, is, that the thunder bird and the lippocampus-shaped monsters, or lightning, fight with and kill the whale in a storm at sea; and that after that is over the bird seizes some of his former allies and bears them off to the mountains, where he tear's them to pieces.

From the samo source, I learned a fact which I had not heard mentioned beforo, which tends to show that the effect of the whites on the Indians, aside from all missionary work, has not been altogether harmful. It is, that whereas each village was stockaded and guarded on the first coming of the whites, and they were even warlike enough to drive the Spanish out of a fort, which they built at Meah Bay, now they have no stockades and very little warfare among themselves, and a few unprotected whites are now living safely among them. But I must close this long communication.

I am, very respectfully, your ob't scrv't, David MACK, Jn., Assistant Surgeon U. S. N.

\title{
CONTAGIOUSNESS OF CHOLERA.
}

By Peter D. Warsh, M.D.

[Communicated for the Boston Medical and Surgical Journal.]

In the summer of 1848 the cholcra visited Ireland, and made its appearance in July of the same year in the city of Waterford, which contains about 80,000 inliabitants, is built on low marshy land, of granite and brick, and has a beautiful harbor, into which the whole drainage of the eity is directed. The tenement houses were well regulated and not crowded. Sanitary regulations were well attended to by the city authorities, and still the cholera made a fearful haroc ere its progress could be stayed.

A friend of mine, who lived at a distance of six miles, made her forenoon call to the city on business, returned carly in the afternoon, 
and sickened that night. A physician was summoned early the next morning, who pronounced her disease cholera, and she died early that evening. Next in turn, a sister, aged 20, was attacked, and also a female domestic, who washed the linen of the deceased the day after the burial; she lived only twenty-four hours after expo. sure. A sister to the man of the house noxt became affected, and she lived only some forty hours. The lady of the house, aged 60, took ill, and died in two days and one night. A daughter, aged 23, next died, in the space of a few hours. A niece of the old lady, aged 30, was taken ill and died in twenty-four hours; a younger sister, aged 18, lived only a few hours. The young man of the house, aged 25, residing in the same street, attended to the burial of his family, and took ill and died in a few hours; also, his wife was attacked with the disease at her own house, but recorcred, much exhausted. The old gentleman, proprietor of the house, still survived; friends and neighbors deserted him, and he stood alone in the world, with the exception of one man-servant, who did not leave him in the hour of his affliction. He was totally shut out from the world, and lived in this solitary way for twenty days. On the twentieth day he was taken ill with the cholera, and only lasted a few hours. He was 60 years old. Total number of deaths, ten, in twenty-one days; leaving not a soul in the family.

The house where this disease appeared was located on an eminence, at the angle of a small street, in a village of about 1500 inhabitants; it was one hundred feet in front, three stories in height, built of brick, and had no cellar. It was well ventilated, and the outbuildings, at a considerable distance from the $d$ welling, were all in perfect order, with everything to promote health and comfort. Some few of the neighbors became victims of the disease at the time, and farmers who were compelled to visit the city were taken home corpses. At length the city became almost totally deserted, peoplo wending their way for safoty to tho country; dwelling-houses and market places were partially closed, and all were in despair. The disease made its exit from the city at the cxpiration of five weeks.

I am thoroughly conversant with the facts above stated, as I resided within a mile of the place at the time-the greater portion of the family affected being my own relations.

CLINICAL LECTURES ON AMBLYOPIA AND AMAUROSIS, BY PROF. A. VON GRAEFE.

[Continued from pago 422.]

CaSE IV.-Cerebral Hemiopia, occurring on similar Sides, stationary, resulting from an Apoplectic Attack.

August K., weaver of fine cloth, 68 years old, comes to us on account

Vox. LxxIII.-No. 22* 